\title{
Plasticity of Synapses in the Rat Neostriatum after Unilateral Lesion of the Nigrostriatal Dopaminergic Pathway
}

\author{
C. A. Ingham, S. H. Hood, P. Taggart, and G. W. Arbuthnott \\ University of Edinburgh Centre for Neuroscience and Department of Preclinical Veterinary Sciences, University of \\ Edinburgh, Summerhall, Edinburgh, United Kingdom EH9 1QH
}

In the 6-hydroxydopamine model of Parkinson's disease in the rat, there is a significant reduction in the number of dendritic spines on the principal projection neurons in the neostriatum, presumably attributable to loss of the nigrostriatal dopamine input. These spines invariably receive input from terminals forming asymmetric synapses that originate mainly from the cortex. The object of the present study was to determine the fate of those terminals after the loss of dendritic spines. Unbiased estimates of synaptic density and absolute numbers of synapses in a defined volume of the neostriatum were made using the "disector" and Cavalieri techniques.

Numerical synaptic density of asymmetric synaptic contacts was $17 \%$ lower in the neostriatum deprived of dopamine innervation and, in absolute terms, there were 3 billion (19\%) fewer contacts. The numerical density of a subpopulation of asymmetric contacts on dendritic spines that have complex or per- forated synaptic specializations and normally make up $9 \%$ of the asymmetric population was $44 \%$ higher on the experimental side. Asymmetric synapses were found to be enriched in glutamate using postembedding immunogold labeling.

The present observations demonstrate that the loss of spines previously reported after 6-hydroxydopamine lesions is accompanied by a loss of asymmetric synapses rather than by the movement of synapses from spines to other postsynaptic targets. The study also demonstrates that there is an increase in complex synaptic interactions that have been implicated in synaptic plasticity in other regions of the CNS after experimental manipulations.

Key words: Parkinson's disease; 6-hydroxydopamine; neostriatum; nigrostriatal pathway; corticostriatal pathway; plasticity; caudate; putamen; spines; perforated synapses
The main synaptic input to dendritic spines in the neostriatum is excitatory and is derived from the cortex and thalamus. The synaptic contacts are on the heads of spines, they are large with asymmetric membrane specializations, and they sometimes have complex shapes (Kemp and Powell, 1971a; Somogyi et al., 1981; Meshul and Casey, 1989; Chen and Hillman, 1990). A proportion of spines also receive a second synaptic input, which usually has small symmetric membrane specializations, and a high proportion of them have been proposed to be dopaminergic (Freund et al., 1984).

Parkinson's disease is characterized by the loss of dopaminergic neurons in the substantia nigra pars compacta, which normally provide dopaminergic input to the caudate nucleus and putamen (neostriatum). A well characterized animal model of Parkinson's disease is the unilateral destruction of the dopaminergic pathway in rats by administration of 6-hydroxydopamine (6-OHDA) (Ungerstedt and Arbuthnott, 1970). In this model morphological changes have been observed in the neostriatum, including a $12-19 \%$ decrease in the density of dendritic spines on the most common type of neostriatal neuron, the medium-sized spiny neuron (Ingham et al., 1989, 1993). This decrease in density of dendritic spines is assumed to be a response to the loss of the dopaminergic input to the spines. This finding raises the question

Received Dec. 29, 1997; revised March 23, 1998; accepted March 26, 1998.

This study was supported by the Wellcome Trust, UK (Grant 040197). We thank Drs. O. P. Ottersen and J. Storm-Mathisen for provision of glutamate antiserum and Prof. J. P. Bolam for discussions throughout the study, especially during preparation of this manuscript. Correspondence should be addressed to Dr. C. A. Ingham, University of Edinburgh Centre for Neuroscience, R(D)SVS, Department of Preclinical Veterinary Sciences, Summerhall, Edinburgh, EH9 1QH, UK.

Copyright (C) 1998 Society for Neuroscience $0270-6474 / 98 / 184732-12 \$ 05.00 / 0$ of the fate of excitatory terminals that form asymmetrical synapses at the head of the spines. There are two possibilities: (1) terminals may move to an alternative postsynaptic target; or (2) they may degenerate. The object of the present study is to test these possibilities using unbiased design-based stereological methods (Sterio, 1984; Coggeshall, 1992) to estimate the numerical density and absolute numbers of asymmetric synaptic contacts in the neostriatum after unilateral 6-OHDA lesions.

\section{MATERIALS AND METHODS}

\section{6-Hydroxydopamine lesion and behavioral testing}

Adult male Wistar rats (200-250 gm; Charles River Laboratories, Margate, UK) were used in this study. Housing conditions and all procedures that were performed on them were in accordance with the Animals Act of 1986 for scientific procedures and were in accordance with the policy on the use of animals in neuroscience research issued by the Society for Neuroscience. The dopaminergic nigrostriatal pathway was unilaterally destroyed as described previously (Ingham et al., 1993) in seven rats. Thirty minutes after treatment with pargyline $(50 \mathrm{mg} / \mathrm{kg}$ in saline, i.p.; Sigma, Poole, UK) and desmethylimipramine $(25 \mathrm{mg} / \mathrm{kg}$ in saline, i.p.; Sigma), the rats were anesthetized with halothane in air (1-2\%) and injected with $2 \mu \mathrm{l}$ of saline containing $6 \mu \mathrm{g}$ 6-OHDA (Sigma) and $0.4 \mu \mathrm{l}$ of ascorbic acid into the left medial forebrain bundle. The stereotaxic coordinates were as follows: anteroposterior, $5.2 \mathrm{~mm}$ anterior of the interaural line; lateral, $1.7 \mathrm{~mm}$ lateral of bregma; and ventral, $8.2 \mathrm{~mm}$ ventral to the brain surface. The success of the lesion was tested (Ungerstedt and Arbuthnott, 1970) 9 or $10 \mathrm{~d}$ after the operation by determining the number of turns the animals make in response to the administration of apomorphine $\left(0.25 \mathrm{mg} / \mathrm{kg}\right.$ in $\mathrm{H}_{2} 0$, i.p.; Research Biochemicals, St Albans, UK). Those animals that turned $>200$ complete circles away from the injected side in 45 min were used for further study and were considered to have at least $90 \%$ loss of dopamine from the lesioned side (Hefti et al., 1980). 


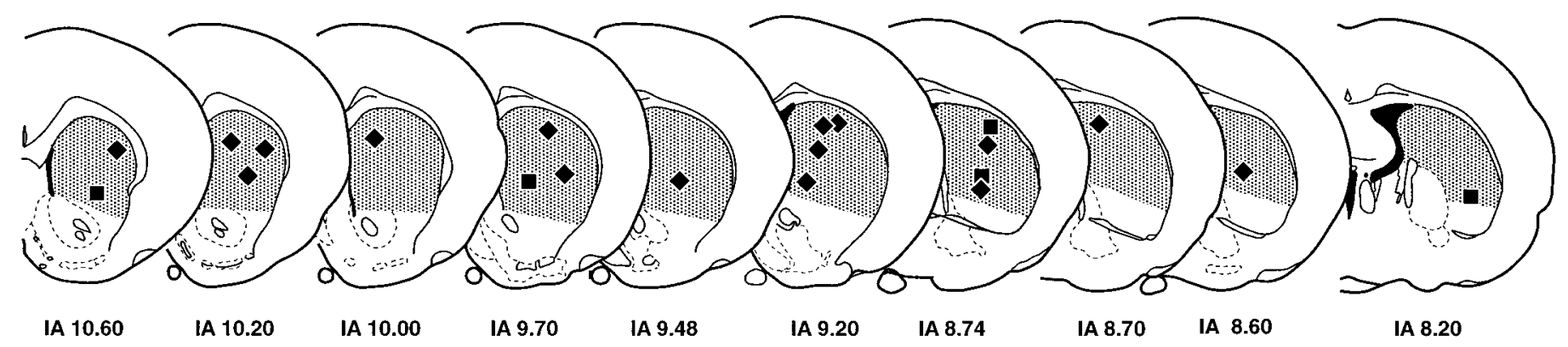

Figure 1. Drawings of coronal sections through the rat brain (Paxinos and Watson, 1982) showing the region of neostriatum considered in the present study (shaded area). The anterior limit was taken as the place in which the corpus callosum crosses the midline, and the caudal limit was the place in which the fornix joins the diencephalon. The dorsal limit was the corpus callosum, and the ventral limit was an imaginary line drawn from the bottom of the lateral ventricle to the rhinal fissure. The black boxes show where samples were taken for estimation of synaptic density. The same region on each side of individual animals was compared.

\section{Tissue preparation}

Twenty-six days after the lesion the rats were anesthetized with sodium pentobarbitone $(60 \mathrm{mg} / \mathrm{kg}$, i.p.) and perfused through the aorta with calcium-free Tyrodes solution at $37^{\circ} \mathrm{C}$ for $30 \mathrm{sec}$ followed by $500 \mathrm{ml}$ of warm fixative at $37^{\circ} \mathrm{C}$ for $5 \mathrm{~min}$ and $700 \mathrm{ml}$ of cold fixative at $4^{\circ} \mathrm{C}$ for 20 min. The fixative consisted of $2 \%$ paraformaldehyde and $2.5 \%$ glutaraldehyde in $0.1 \mathrm{M}$ sodium phosphate buffer, $\mathrm{pH} 7.4$ (PB). Coronal sections of $70 \mu \mathrm{m}$ were cut on a vibrating microtome (Vibratome, Lancer) in PB. Sections were collected from the level at which the corpus callosum first crosses the midline (10.6 mm anterior of the interaural line) to where the fornix joins the diencephalon ( $8.2 \mathrm{~mm}$ anterior of the interaural position) (Paxinos and Watson, 1982). Every third section was taken for analysis; however, the choice of whether the first, second, or third section cut was used was determined at random so that the volume of the neostriatum could be estimated using the Cavalieri method (Coggeshall, 1992). The sections were washed in $\mathrm{PB}$, treated with $1 \%$ osmium tetroxide in PB for $40 \mathrm{~min}$, dehydrated, embedded in resin, and mounted on microscope slides (Ingham et al., 1993).

\section{Quantitative analysis}

The Cavalieri method for estimating the volume $\left(\mathrm{V}_{\text {ref }}\right)$. The sections through the neostriatum were digitized by placing the slides on a light box and viewing them with a macro lens attached to a video camera. The area of the neostriatum on each side of every section was measured (using NIH Image software) and then the following formula was applied:

$$
V_{\mathrm{ref}}=a \times t \times s
$$

where $a$ is the mean area of neostriatum, $t$ is the thickness of the vibratome sections $(70 \mu \mathrm{m})$, and $s$ is the total number of sections through the defined region of neostriatum (usually 30 ).

A specified region of the neostriatum was considered, which could be easily defined with unambiguous anatomical boundaries. The anterior and posterior boundaries have been described above. The corpus callosum defines the dorsal and lateral boundaries, the lateral ventricle defines the medial edge, and an arbitrary ventral boundary consisted of a line drawn from the ventral tip of the lateral ventricle to the rhinal fissure. The globus pallidus was excluded from this defined region in sections in which the imaginary line crossed its borders (Fig. 1).

Electron microscopic sampling. Regions from three sections (chosen by systematic random sampling) through the experimental and contralateral neostriata of each animal were selected randomly by dropping a square card $\left(1 \mathrm{~cm}^{2}\right)$ from $15 \mathrm{~cm}$ above the appropriate figure of the rat atlas (Paxinos and Watson, 1982) (Fig. 1) and accepting it if it fell within the neostriatum. The same region on both sides of the brain was excised and reembedded as described previously (Bolam, 1992), giving a total of 42 blocks. Serial sections (silver) were cut ( $\sim 10$ per grid) and collected on Formvar-coated copper slot grids, stained with lead citrate, and examined in a Philips 400 electron microscope (EM). The disector analysis of each block was performed on 15 pairs of electron micrographs (final magnification, $25,000 \times$ ) from two adjacent sections of a similar thickness (Hunter and Stewart, 1993). A systematic random-sampling method was used whereby each micrograph was taken at least two widths of the EM screen apart. All structures were included in the sampling method, i.e., groups of myelinated fibers, cell somata, and blood capillaries. Regions obscured in some way, e.g., with folds or contamination were avoided. Each pair of electron micrographs represent two disectors with micrograph 1 acting as the reference section and micrograph 2 as the "look up" section and vice versa (Figs. 2, 3).

\section{Identification of synapses}

Synapses were recognized on the micrographs by the accumulation of at least three synaptic vesicles at the presynaptic site, a widened synaptic cleft with parallel presynaptic and postsynaptic membranes, and a thickened postsynaptic membrane (Figs. 2, 3). Asymmetric synapses possessed a marked postsynaptic density, whereas symmetric synapses only had a slight thickening adjoining the membrane. The synapses and their associated postsynaptic targets were identified as asymmetric-soma, asymmetric-dendrite, asymmetric-spine, or asymmetric-? (when it was not possible to unequivocally identify the postsynaptic target). Symmetric synapses were classified in the same way. Complex or perforated synaptic contacts, defined by discontinuous specializations, were identified as were boutons in synaptic contact with more than one postsynaptic target. Spines with two asymmetric contacts from different boutons were also noted. A rectangular unbiased counting frame $\left(44.58 \mu \mathrm{m}^{2}\right)$ (Gundersen, 1977) was placed over the micrographs, and the parameters outlined below were recorded on a spreadsheet (Microsoft Excell).

\section{Estimation of mean synaptic numerical density $\left(\mathrm{N}_{v \text { syn }}\right)$}

Synaptic number per cubic micrometer was calculated using the formula:

$$
N_{\mathrm{v} \text { syn }}=\sum \mathrm{Q}-{ }_{\text {syn }} /(\mathrm{hxA})
$$

adapted from Sterio (1984) and De Groot and Bierman (1986), where: $\mathrm{Q}-{ }_{\text {syn }}$ are synapses present in the reference section but not the look up section (referred to as "tops"); $h$ is distance between disector planes (i.e., section thickness), and $A$ is sample area.

\section{Estimation of absolute numbers of synapses (N)}

$$
N=N_{\text {v syn }} \times V_{\text {ref }}
$$

\section{Estimation of section thickness}

Section thickness was determined using the minimal fold method. At least three suitable folds were located on the sections used and photographed at a magnification of $70,000 \times$. Section thickness was estimated to be half of the mean width of the measured folds (Small, 1968).

\section{Postembedding immunogold labeling}

Sections from a pair of samples taken from one animal were processed at the same time for postembedding immunogold labeling using an antiserum to glutamate and a variation of the immunogold procedure used previously (Phend et al., 1992). In brief, serial sections (gold interference color) were cut $(\sim 10$ per grid), collected on Formvar-coated gold slot grids, and rinsed three times for $10 \mathrm{~min}$ each in $0.05 \mathrm{M}$ Tris-PBS containing $0.01 \%$ Triton X-100 (TPBS-TX) before incubation in primary antiserum. All incubations and rinses were performed at room temperature. The anti-L-glutamate serum (code 03 ) was kindly provided by Drs 


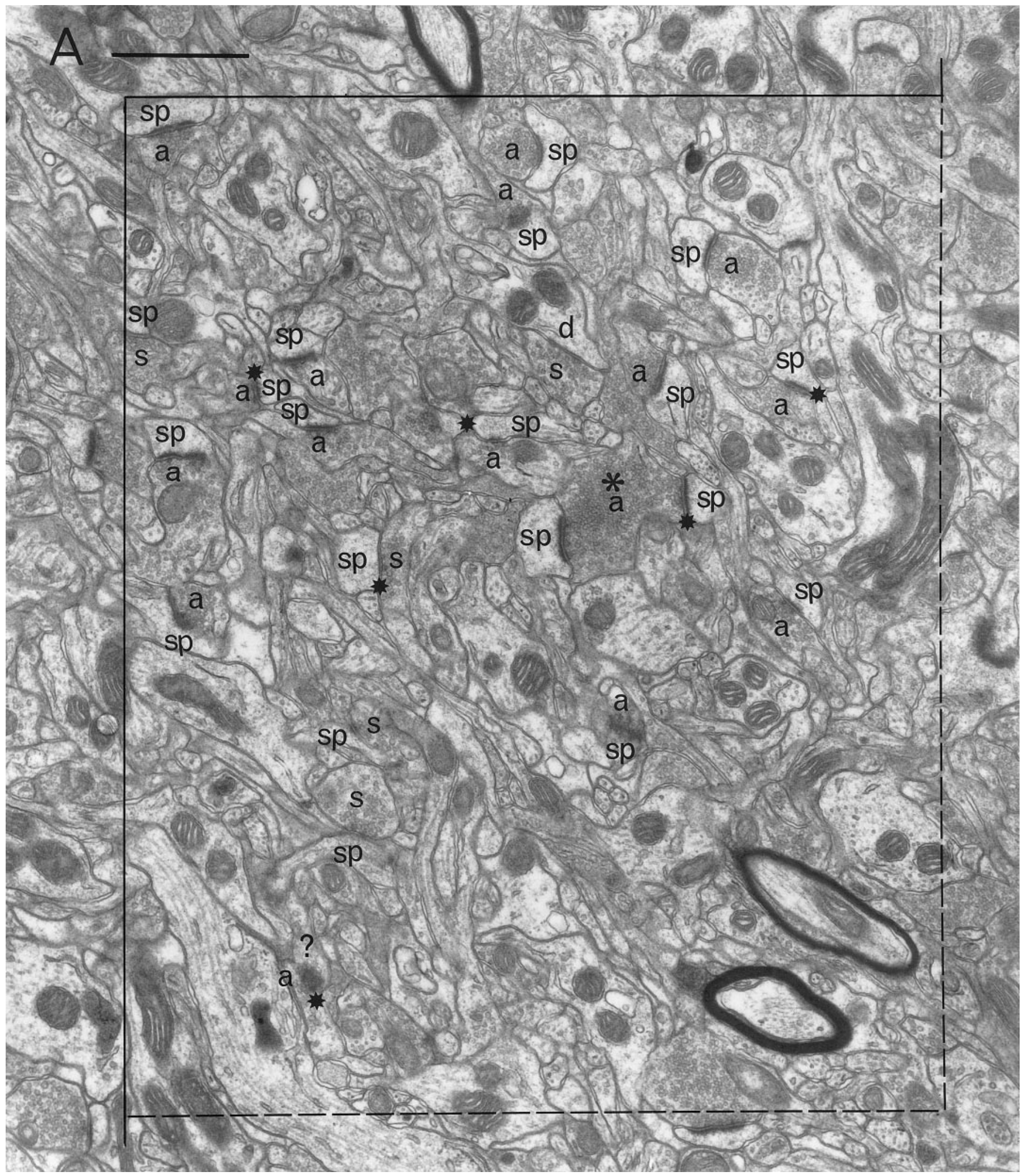

Figure 2. A pair of electron micrographs taken from serial sections through the neostriatum (contralateral side). Synapses that were within the unbiased counting frame are labeled. Synaptic contacts are labeled according to their membrane specialization ( $a$, asymmetric; $s$, symmetric) and their postsynaptic targets ( $s p$, spine; $d$, dendrite; ?, unknown). Stars mark tops of synapses, i.e., those found in the reference but not the look up section. Asterisks mark presynaptic boutons that make synapses with two different postsynaptic targets. Each micrograph was used as the reference and as the look up with its matching pair. Scale bar, $1 \mu \mathrm{m}$. 


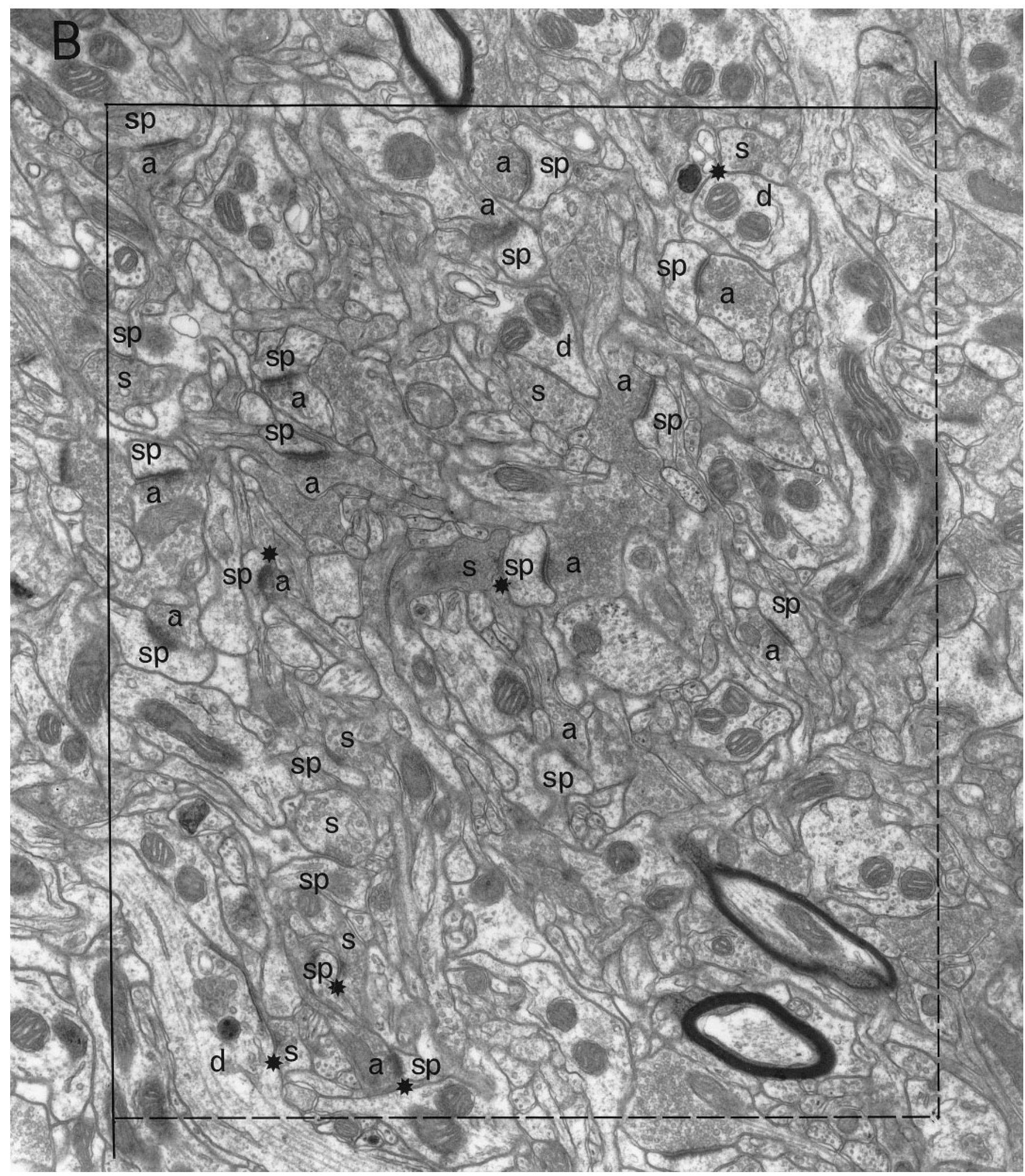

Figure 2 continued

O. P. Ottersen and J. Storm-Mathisen and was used at a dilution of 1:500. Properties of this antiserum have been described previously, including that it recognizes glutamate fixed to protein with glutaraldehyde (Ottersen and Storm-Mathisen, 1984). The antiserum weakly cross-reacts with glutamine and aspartate, but this is abolished after preincubation of the antiserum with $100 \mu \mathrm{M}$ glutaraldehyde conjugates of these amino acids (Maxwell et al., 1992). This procedure was therefore performed. The primary antiserum was diluted with TPBS-TX containing $1 \%$ normal goat serum, and sections were incubated for $\sim 18 \mathrm{hr}$. Further washes in TPBS-TX were followed by incubation in anti-rabbit IgG coupled to 15 $\mathrm{nm}$ colloidal gold at a dilution of 1:10 in TPBS-TX for $2 \mathrm{hr}$. Finally, after washing, the grids were stained with $1 \%$ aqueous uranyl acetate for 15 


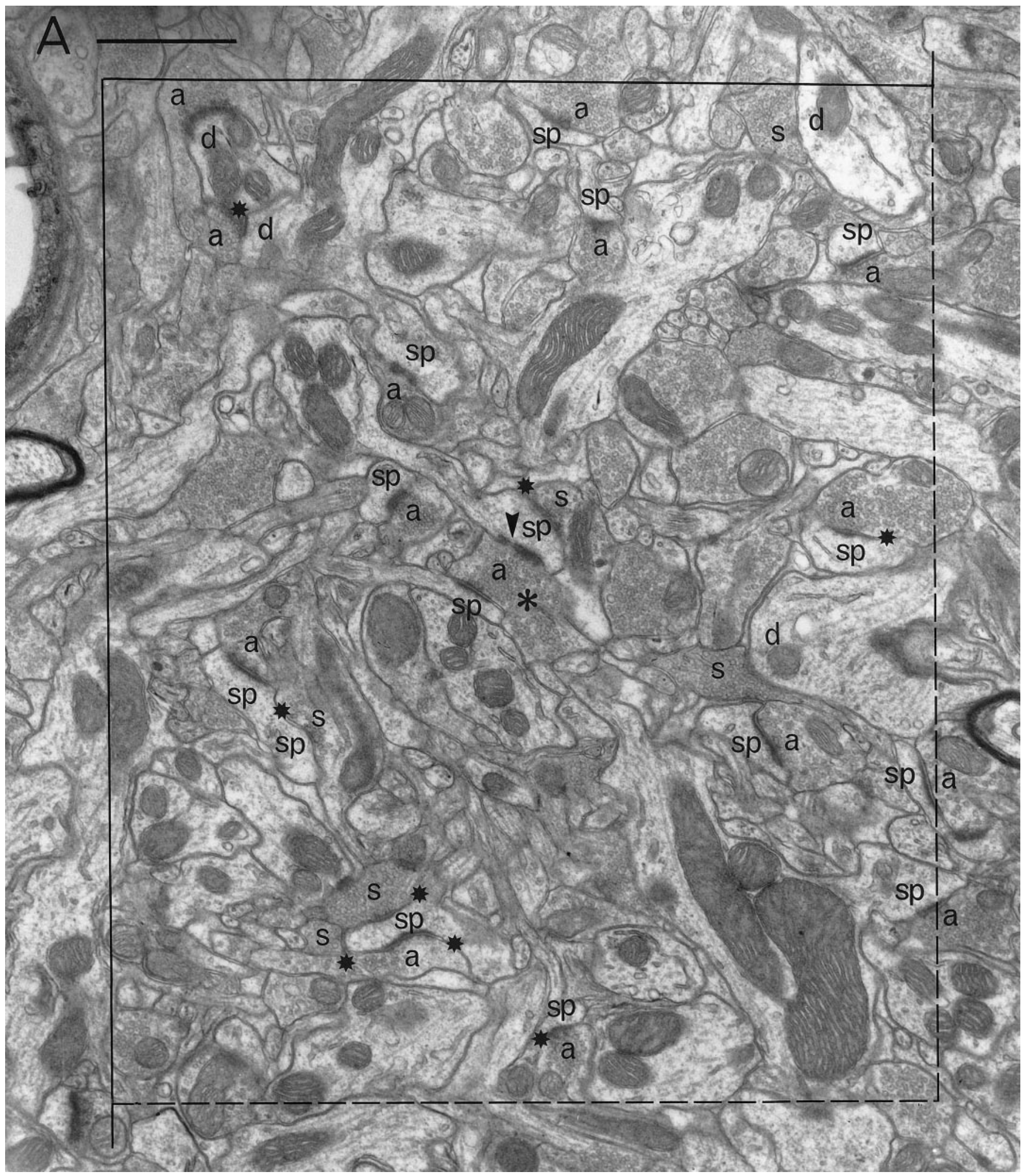

Figure 3. A pair of electron micrographs taken from serial sections through the neostriatum (experimental side). Synapses that did not cross the forbidden lines of the the unbiased counting frame are labeled. Synaptic contacts are labeled according to their membrane specialization $(a$, asymmetric; $s$, symmetric) and their postsynaptic targets ( $s p$, spine; $d$, dendrite; ?, unknown). Stars mark tops of synapses, i.e., those found in the reference but not the look up section. Asterisks mark presynaptic boutons that make synapses with two different postsynaptic targets. Arrowheads mark the discontinuities of complex synaptic contacts. Each micrograph was used as the reference and as the look up with its matching pair. Scale bar, $1 \mu \mathrm{m}$. 


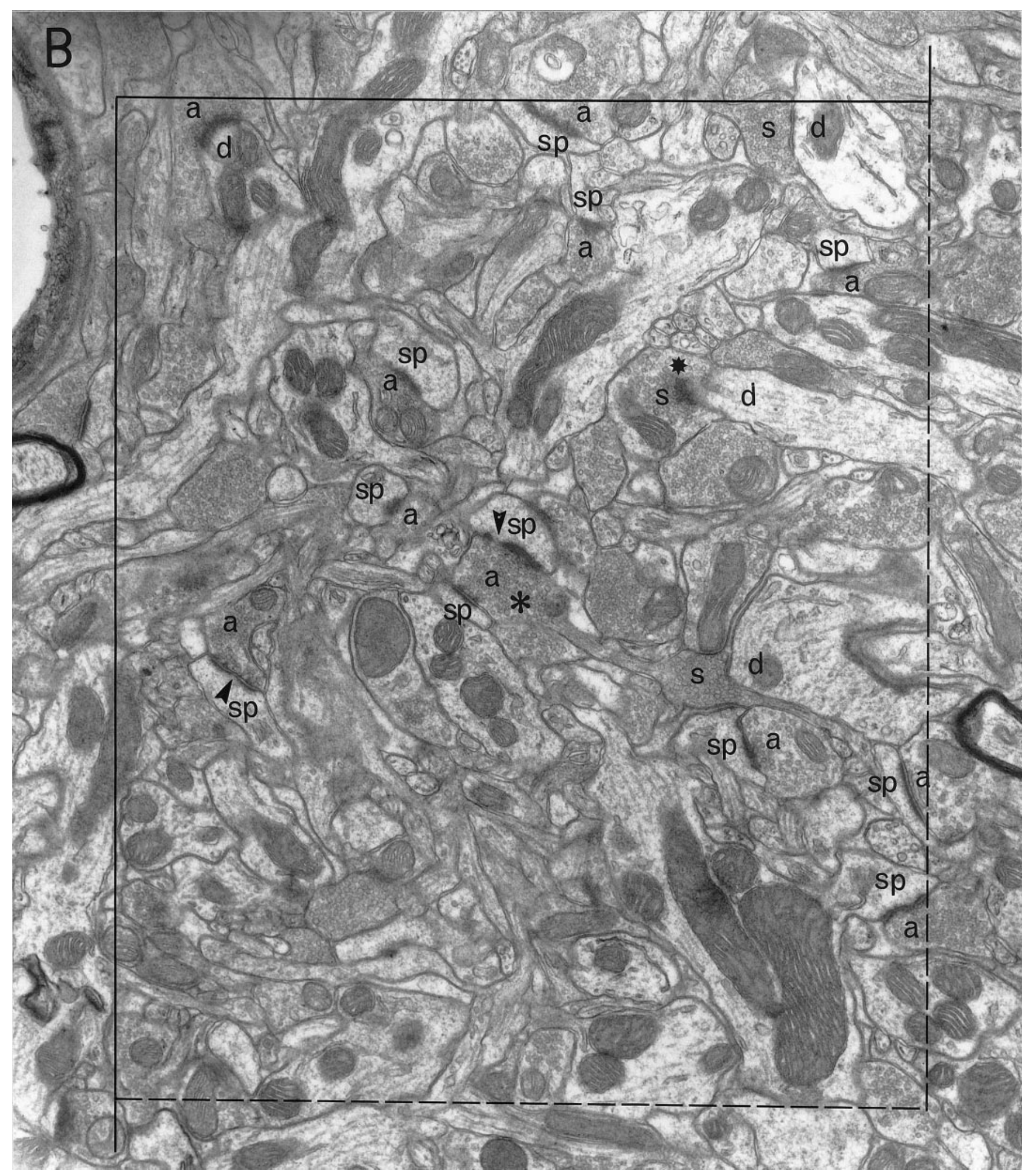

Figure 3 continued

min and lead citrate for 2.5 min (Reynolds, 1963), and they were examined in a Philips 400 EM.

A systematic random-sampling method was used to collect 15 electron micrographs from a single section (final magnification, 25,000 $\times$ ) whereby each micrograph was taken at least two widths of the EM screen apart. The electron micrograph negatives were digitized at a resolution of 500 dots per inch using a UC 1200 S scanner (Umax Data Systems Inc.). The density of gold particles and the cross-sectional areas were calculated for all asymmetric-spinous synaptic boutons, all symmetric synaptic boutons, and all postsynaptic structures to these synapses. Gold particle density was also calculated over the lumen of any blood capillaries present. The calculations were made using a grain counting program 


\begin{tabular}{|c|c|c|}
\hline & $\begin{array}{l}\text { Contralateral } \\
\text { side }(\%)\end{array}$ & $\begin{array}{l}\text { Experimental } \\
\text { side }(\%)\end{array}$ \\
\hline \multicolumn{3}{|c|}{ Asymmetric synapses } \\
\hline Dendrites & 5 & 9 \\
\hline Spines & 72 & 71 \\
\hline Unidentified & 23 & 20 \\
\hline \multicolumn{3}{|c|}{ Symmetric synapses } \\
\hline Soma & 3 & 4 \\
\hline Dendrites & 40 & 51 \\
\hline Spines & 44 & 34 \\
\hline Unidentified & 14 & 12 \\
\hline
\end{tabular}

(Newgrains) written for the purpose on a Sun SPARCstation 20 Unix workstation (Ingham et al., 1997). Statistical comparisons were made (Statview II, Apple Macintosh) using unpaired Student's $t$ tests and one-way ANOVA with post hoc means tests.

\section{RESULTS}

Ninety disectors (30 from each of three blocks) were analyzed from each contralateral and experimental neostriatum from seven animals (total of 1260 disectors). Asymmetric contacts accounted for $77-80 \%$ of synapses, whereas symmetric contacts accounted for only $20-23 \%$. Boutons making asymmetric contacts generally contained small spherical clear vesicles, and their postsynaptic targets were usually dendritic spines or structures that could not be unequivocally identified (Table 1). Dendritic shafts were also occasionally contacted, whereas cell bodies were not (Table 1). Boutons making symmetrical contacts had pleomorphic synaptic vesicles ranging from small and elongated to large and round; postsynaptic targets included cell bodies, dendritic shafts, and spines (Figs. 2, 3, Table 1).

The numbers of asymmetric contact tops, i.e., those found in the reference but not the look up section, ranged from 143 to 240 on each side of each animal in a defined volume that ranged from 199 to $247 \mu \mathrm{m}^{3}$. The numbers of symmetric contact tops ranged from 30 to 61 in the same volume. The estimated numerical density of asymmetric contacts was significantly lower in the neostriatum on the experimental side (mean reduction of $17 \%$; paired Student's $t$ test, $p<0.05$; Table 2 ). The volume of neostriatum calculated using the Cavalieri method (Eq. 1) ranged from 14.8 to $19.2 \mu \mathrm{m}^{3}$. The absolute number of synapses $(N)$ in the specified region of neostriatum was estimated for each side of each animal (Eq. 3), and the number of asymmetric synapses was found to be significantly smaller (mean reduction of 19\%; paired Student's $t$ test, $p<0.05$; Table 2) on the experimental side.

The mean numerical density estimate of complex or perforated synapses in the experimental neostriatum was significantly higher $(0.11 \pm 0.02 \mathrm{SD})$ when compared with that on the contralateral side $(0.08 \pm 0.02 \mathrm{SD}$; paired Student's $t$ test, $p<0.05$; Figs. 4, $5 C, D)$. Complex synapses formed an average of $9 \%$ of the total asymmetric synapse population on the contralateral side and $15 \%$ of them on the experimental side of the brain. The density of asymmetric synapses onto unidentified targets (asymmetric-?) was significantly lower (paired Student's $t$ test, $p<0.05$; Fig. 4) on the experimental side (24\%; Fig. 4). Similarly, absolute numbers of asymmetric synapses onto spines and those onto unidentified targets (asymmetric-?) were significantly lower on the experimental side (spines, $-20 \%$ lower; unidentified targets, $-27 \%$ lower; Fig. 4).

\section{Immunogold labeling using the L-glutamate antiserum}

Gold particles were distributed throughout the neostriatum, but high densities were observed overlying populations of myelinated and unmyelinated axons, preterminal vesicle-containing structures, and boutons with small round vesicles and asymmetric synaptic specializations (Fig. $5 A, B$ ). In both the contralateral and experimental neostriata, the mean density of gold particles over boutons with asymmetric synaptic contacts on dendritic spines was significantly greater than that over postsynaptic structures or boutons with symmetric synaptic specializations (Table 3 ). Moreover, the gold particle density over these asymmetric boutons was significantly greater on the ipsilateral, dopamine-denervated neostriatum compared with that on the contralateral side. Crosssectional areas of asymmetric and symmetric synaptic boutons and their postsynaptic targets in the neostriata were not significantly different between the two sides of the brain.

\section{DISCUSSION}

The present study shows that there are $19 \%$ fewer asymmetric synapses in the neostriatum that has been deprived of its dopaminergic input compared with the contralateral side where the dopaminergic input is intact. The decrease is not attributable to the loss of the dopaminergic synapses, because the results of studies using a variety of approaches have revealed that dopaminergic terminals form symmetrical synapses (Bouyer et al., 1984; Freund et al., 1984; Voorn et al., 1986; Groves et al., 1994; Smith et al., 1994). This implies that there is a secondary loss of nondopaminergic synapses after removal of the nigrostriatal pathway. The loss of asymmetric synapses is, remarkably, the same as the $19 \%$ decrease in dendritic spine density found on

Table 2. Mean density and absolute numbers of asymmetric and symmetric synapses ( \pm SD) in the contralateral and experimental neostriata of rats $(n=7)$ lesioned with 6-OHDA

\begin{tabular}{|c|c|c|c|}
\hline & Contralateral side & Experimental side & $\begin{array}{l}\text { Percentage change of the } \\
\text { mean from contralateral } \\
\text { side }(\%)\end{array}$ \\
\hline \multicolumn{4}{|l|}{ Asymmetric synapses } \\
\hline Density $/ \mu \mathrm{m}^{3}$ & $0.915 \pm 0.12$ & $0.764 \pm 0.09^{*}$ & -17 \\
\hline Absolute number $\times 10^{9}$ & $16.112 \pm 2.15$ & $13.009 \pm 1.46^{*}$ & -19 \\
\hline \multicolumn{4}{|l|}{ Symmetric synapses } \\
\hline Density $/ \mu \mathrm{m}^{3}$ & $0.235 \pm 0.05$ & $0.223 \pm 0.03$ & -5 \\
\hline Absolute number $\times 10^{9}$ & $4.141 \pm 0.86$ & $3.825 \pm 0.67$ & -8 \\
\hline
\end{tabular}

*Significant difference when contralateral and experimental sides are compared (paired Student's t test, $p<0.05$ ). 
A

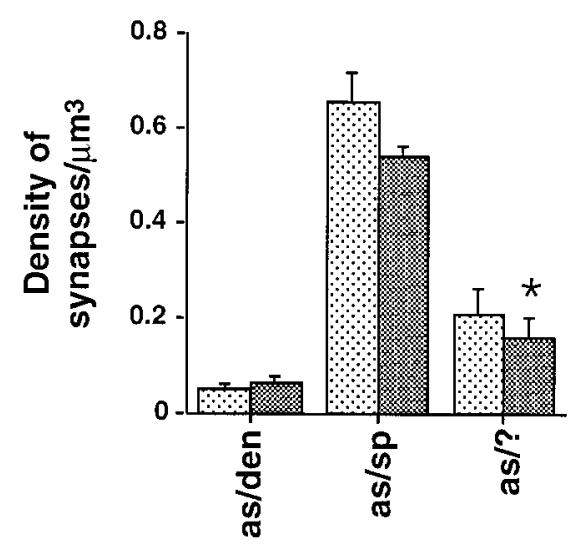

B

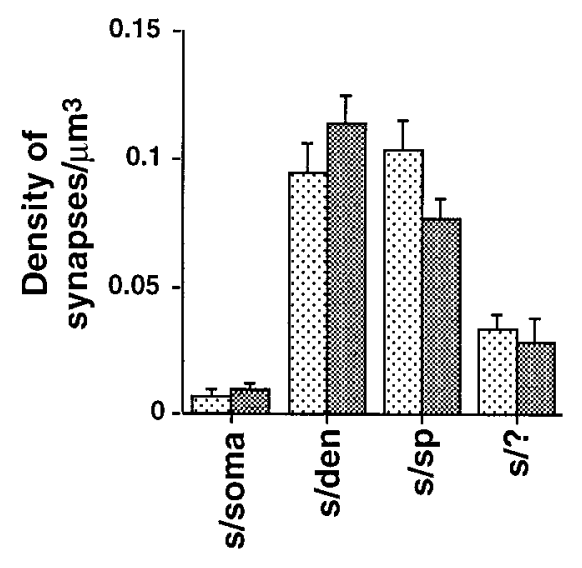

C

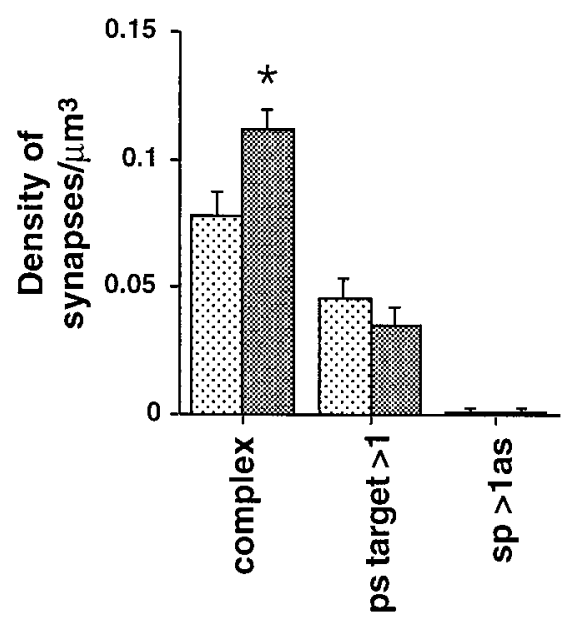

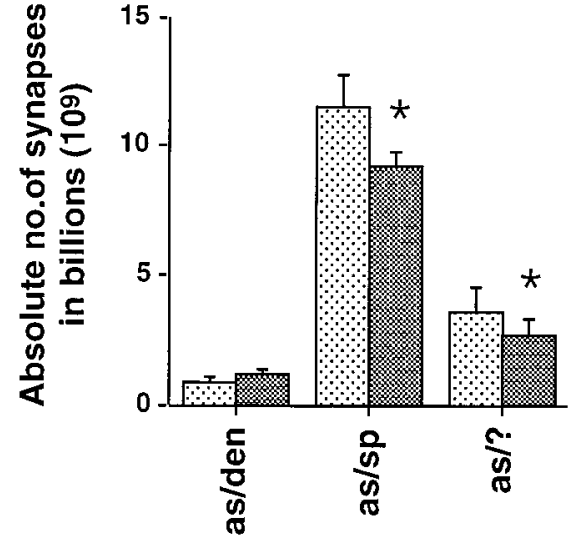
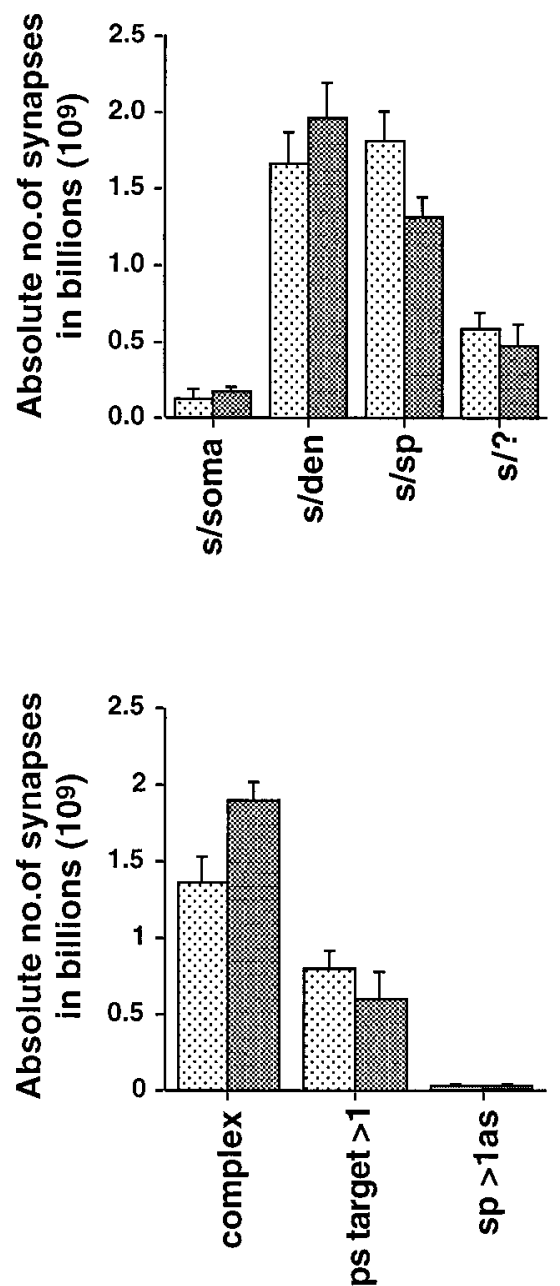

control

experimental

Figure 4. Mean estimates of the numerical synaptic density and the absolute number of synapses in the specified region of neostriatum from the contralateral and experimental sides of 6-OHDA lesioned rats $(n=7$, mean $\pm \mathrm{SE})$. The results are subdivided according to the membrane specialization of synaptic contacts $(A, a s$, asymmetric; $B, s$, symmetric) and according to their postsynaptic targets ( $s p$, spine; den, dendrite; ?, unknown). $C$, Subpopulations of synapses with discontinuous (complex) synaptic contacts, with more than one postsynaptic target ( $p s$ target $>1)$ and a subpopulation of spines receiving two asymmetric synapses $(s p>1$ las $)$. Asterisks show a significant difference when estimates from the contralateral and experimental sides are compared (paired Student's $t$ test, $p<0.05$ ). 

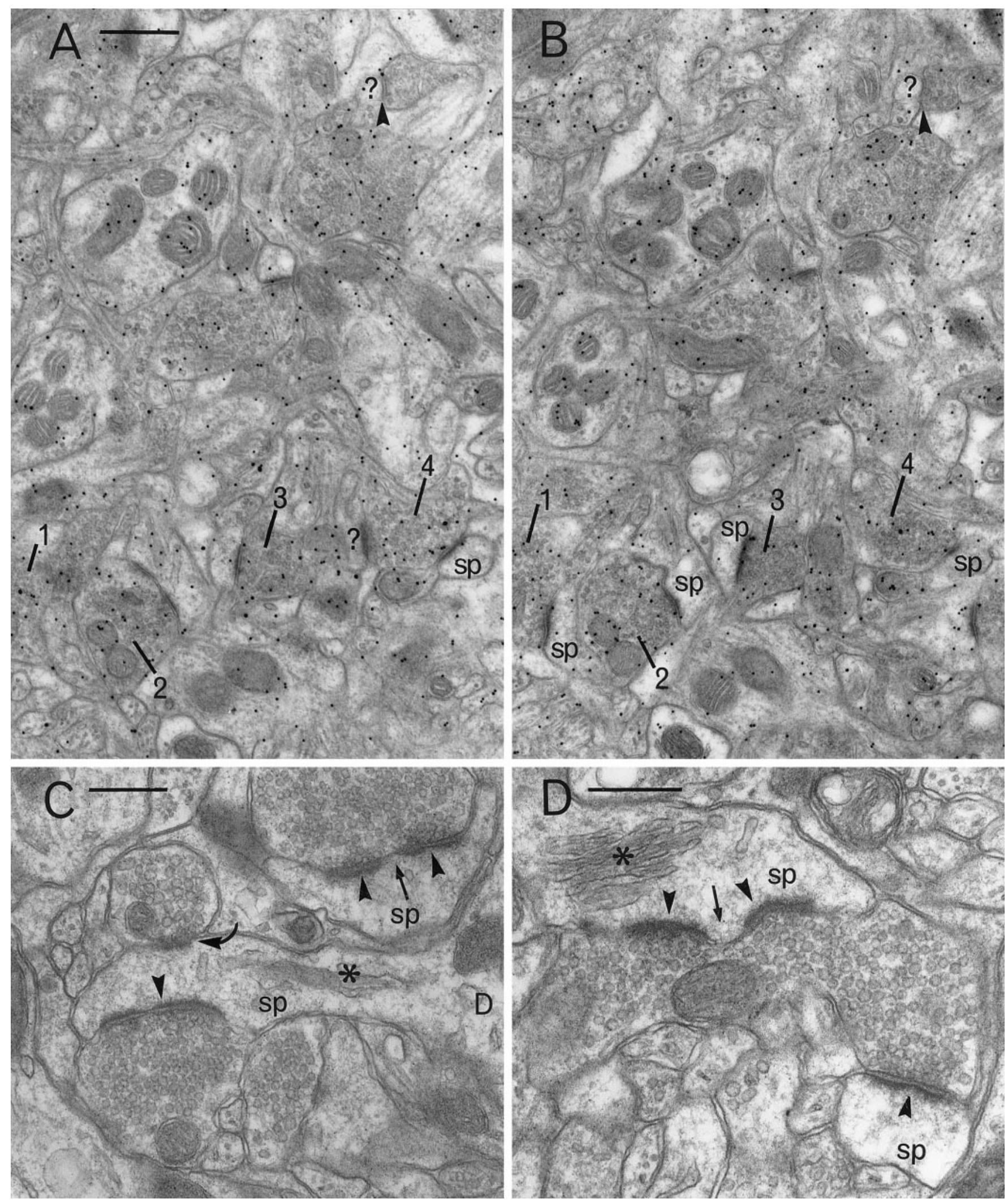

Figure 5. A, B, Pair of electron micrographs taken from serial sections through the neostriatum (contralateral side) that have been immunogold labeled using an antiserum to glutamate. Gold particles are enriched in vesicle-containing boutons that make asymmetric synaptic contacts (four of which are numbered 1-4 in $A, B)$ with spines ( $s p$ ) or unidentified targets (?). Symmetric synapses (arrowheads) and postsynaptic targets ( $s p$, ?) are not enriched in gold particles. $C, D$, Electron micrographs of spines $(s p)$ and their synaptic input taken from the rat neostriatum on the experimental side. Boutons with small round vesicles make obvious asymmetric synaptic contact with spine heads (arrowheads). These contacts are sometimes discontinuous and are therefore classified as complex (arrows). Spines can be recognized by their spine apparatus (asterisks). In $C$, a second bouton with large pleomorphic vesicles makes symmetrical synaptic contact with the head of the spine (curved arrow). Scale bars: $A, B, 0.5 \mu \mathrm{m} ; C, D, 0.3 \mu \mathrm{m}$. 
Table 3. Mean gold particle density ( \pm SD) over different structures in the contralateral and experimental neostriata of one rat lesioned with 6-OHDA

\begin{tabular}{llc} 
& Contralateral side & Experimental side \\
\hline Asymmetric synaptic boutons & $42.4 \pm 15.9(n=142)$ & $52.3 \pm 21.69^{*}(n=120)$ \\
Symmetric synaptic boutons & $20.9 \pm 16.2^{* *}(n=26)$ & $20.7 \pm 13.3^{* *}(n=29)$ \\
Postsynaptic targets & $18.1 \pm 13.5^{* *}(n=174)$ & $22.06 \pm 13.9^{* *}(n=141)$ \\
Capillaries (background) & $2.0^{* *}(n=1)$ & $2.4^{* *}(n=4)$
\end{tabular}

*Significant differences are shown when asymmetric boutons in the neostriatum on each side of the brain are compared (unpaired Student's t test, $p<0.001$ ).

**Significant differences are also apparent when asymmetric boutons are compared to other structures on the contralateral side (one-way ANOVA, F-ratio = 74.6, $p<0.001$; post hoc comparison of the means: Fisher PLSD, $p<0.01$ ) and the experimental side (one-way ANOVA, F-ratio $=75.9, p<0.001$; post hoc comparisons: Fisher PLSD, $p<0.01$ ).

medium-sized spiny neurons $26 \mathrm{~d}$ after a 6-OHDA lesion (Ingham et al., 1989, 1993). Spines form the major postsynaptic target of asymmetric synapses, which confirms previous findings in control material (Kemp and Powell, 1971a). Although 20-23\% of postsynaptic targets were not unequivocally identified in the present material, many of them will also be spines, which would increase the percentage of these postsynaptic targets to $80-90 \%$. The findings of spine and synapse loss complement each other and are consistent with the suggestion that loss of spines after a 6-OHDA lesion is accompanied by a loss of asymmetric synapses on those spines. The population of asymmetric synapses is likely to be of cortical origin (Kemp and Powell, 1971b; Hattori et al., 1978; Somogyi et al., 1981; Bouyer et al., 1984; Xu et al., 1989), although they may also include some thalamostriatal terminals (Kemp and Powell, 1971b; Xu et al., 1991). The enrichment of immunogold labeling in asymmetric boutons using an antiserum to L-glutamate in the present study has also confirmed the glutamatergic nature of the majority of asymmetric synapses in the neostriatum (McGeer et al., 1977; Fonnum et al., 1981; Ingham, 1992).

\section{Effect of unilateral destruction of the nigrostriatal dopamine pathway}

Understanding the significance of a $19 \%$ loss of spines and synapses after dopamine denervation depends on which spines and synapses disappear. There are at least three possibilities: first, spines and synapses may be lost from a specific neuronal subtype; second, there may be a specific origin of the presynaptic synapses that are lost; and third, the loss of dopamine may have a generalized action that is independent of presynaptic or postsynaptic origins of the lost synapses. These will be considered in turn.

First, there are at least two subtypes of medium-sized spiny neurons in the neostriatum that receive synaptic input from dopamine synapses (Freund et al., 1984; Yung et al., 1996). One population of neurons project "directly" to the substantia nigra pars reticulata and colocalize the neuropeptides substance $\mathrm{P}$ and/or dynorphin with GABA, whereas another population of neurons send their axons primarily to the globus pallidus and colocalize the neuropeptide enkephalin with GABA (Penny et al., 1986; Gerfen and Young, 1988). Dopamine denervation may produce a differential response of these two populations, one becoming more vulnerable to spine and synapse loss after the lesion. This question is extremely important because an imbalance of activity in these two pathways is thought to be critical in producing the hyperkinesias or hypokinesias of basal ganglia disorders (Albin et al., 1989; Alexander and Crutcher, 1990; DeLong, 1990).

Spine necks are the primary postsynaptic target of dopamine terminals (Freund et al., 1984; Groves et al., 1994), and those spines that previously received direct dopaminergic synapses onto their necks may be specifically lost. The percentage of spines that receive dopamine synapses is not known, although it has been shown in one identified striatonigral neuron (i.e., directly projecting) that $39 \%$ of spines ( 87 studied between 60 and $100 \mu \mathrm{m}$ from the cell soma) receive both a dopaminergic synapse and an asymmetric synapse (Freund et al., 1984). However, in other studies, it can be estimated that $<8 \%$ of spines receive dopaminergic input (Wilson et al., 1983; Groves et al., 1994). In the current study it is possible to relate the numbers of asymmetric and symmetric synapses onto spinous postsynaptic targets and estimate that $15 \%$ of dendritic spines receive both an asymmetric and symmetric synapse in control neostriatum. However, it should be pointed out that not all symmetric synapses will contain dopamine, and so our figures are closer to the lower densities estimated in other studies (Wilson et al., 1983; Groves et al., 1994). It is also important to note that the estimates of symmetric synaptic densities in the current study may be inaccurate because of the small numbers counted overall (Coggeshall, 1992). The combined data from the current and previous studies (Wilson et al., 1983; Freund et al., 1984; Groves et al., 1994) suggest that the percentage of spines that receive dopamine synapses is not consistent and could differ depending on the projection site of the output neuron, the chemical compartment (patch or matrix), or even on the part of the dendrite examined.

The second possibility is that the source of the asymmetric synapses on spine heads determines which synapses and spines are lost. Two morphologically distinct corticostriatal pathways have been observed in rats from both agranular cortex (Wilson, 1987) and sensory "barrel cortex" (Wright et al., 1995). Moreover, ipsilateral- and contralateral-projecting motor corticostriatal terminals may contact different proportions of dendrites and spines as well as differing proportions of D1 and D2 receptor proteinimmunoreactive targets (Hersch et al., 1995); see Hanley and Bolam (1997) for alternative findings.

Finally, the loss of synapses and spines may be a random process. This would imply that dopamine subserves a neurotrophic function and could play a role in the maintenance of spines. Indeed, the dopamine-containing cells have been shown to contain neurotrophins of various classes, including BDNF and NT3 (Seroogy et al., 1994), and it may be the release of these factors, rather than dopamine, that is important for spine survival.

In contrast to the overall loss of asymmetric synapses, there was a significant increase in the numerical density of a subpopulation of asymmetric synapses. This subpopulation has complex, discontinuous synaptic specializations that may be perforated. These 
synapses normally make up $\sim 9 \%$ of the asymmetric synaptic population, but this increases by $44 \%$ so that $15 \%$ of asymmetric synaptic specializations are complex after dopamine denervation. The estimate of absolute number was not significantly different; however, the small number of tops counted in each analysis (10-30) could easily explain the inability to detect a significant difference.

An increase in the proportion of perforated to nonperforated synapses has been suggested to occur in the putamen of parkinsonian patients and after dopamine receptor blockade in rats with haloperidol (Meshul et al., 1992, 1994; Meshul and Tan, 1994; Anglade et al., 1996), although unbiased methodology was not used in any of these studies. There is evidence that synapses with complex or perforated postsynaptic densities have increased efficacy, and they have been implicated in synaptic remodeling in the hippocampus in which their numbers increase with long-term potentiation (Calverley and Jones, 1990; Geinisman et al., 1991; Lisman and Harris, 1993; Harris and Kater, 1994; Pierce and Lewin, 1994). Loss of a specific population of asymmetric synapses and an accompanying increase in a specific population of perforated asymmetric synapses could have very important functional consequences that may play a major role in the development of Parkinson's disease. It is not known whether complex synaptic specializations in the neostriatum have a specific source or postsynaptic target. This is of key importance, because an increase of complex synaptic specializations on the neurons that project indirectly to the substantia nigra via the globus pallidus could explain the increased activity in this pathway and the results suggesting an overactivity in the corticostriatal pathway after dopamine denervation (Lindefors and Ungerstedt, 1990; Greenamyre and O'Brien, 1991). The link between overactivity in a corticostriatal projection and the striatopallidal pathway is also consistent with results showing a reversal of changes in preproenkephalin mRNA levels after cortical lesions (Campbell and Björklund, 1994) or blockage of NMDA receptors (Hajji et al., 1996).

Suggestions of glutamate hyperactivity in Parkinson's disease have been addressed in animal models, and joint treatment with low doses of NMDA antagonists markedly potentiates the therapeutic effects of dopaminergic agonists (Greenamyre and O’Brien, 1991; Starr, 1995; Blandini et al., 1996). Suggested anatomical locations for this action have included the subthalamic nucleus, the substantia nigra, and the neostriatum. There is preliminary evidence for a striatal location, because structural alterations in the neostriatum after neuroleptic treatment were reversed by NMDA antagonists (Meshul et al., 1994). The present study also showed increased immunogold labeling indicating an increased concentration of glutamate (Ottersen, 1989) in asymmetric synaptic boutons, which could be a further indication of hyperactivity in the remaining boutons. This finding however, needs confirmation.

\section{Symmetric synapses}

The estimated numerical density and absolute number of symmetric synapses were not significantly lower in the experimental neostriatum. Symmetric synapses formed $\sim 20 \%$ of the total synaptic population in the contralateral neostriatum. Dopaminergic boutons probably make up $\sim 9 \%$ of the total number of synapses and always make symmetrical synaptic contacts (Freund et al., 1984; Groves et al., 1994); see Hattori et al. (1991) for an alternative view. It is surprising that a $9 \%$ decrease in symmetric synapses was not detected in the present study. There are at least three explanations for this: (1) the small number of symmetric synapse tops counted may not produce a reliable estimate of their synaptic density (Coggeshall, 1992); (2) the smallest symmetric synapses that are likely to include the dopaminergic population are sometimes hard to identify and could therefore be underestimated; and (3) there may have been compensatory sprouting of other populations of nerve fibers. Morphological plasticity has been shown to occur in enkephalin-immunoreactive axon collateral and terminal boutons of medium-sized spiny neurons in the rat neostriatum and globus pallidus after unilateral 6-OHDA lesion of the nigrostriatal pathway (Ingham et al., 1991, 1997).

In summary, this study shows that corticostriatal (and/or thalamostriatal) synapses are lost as a result of dopaminergic denervation. If a similar loss occurs in Parkinson's disease, then it could be contributing to the symptomology of the human disorder and could be specifically targeted in novel therapeutic strategies.

\section{REFERENCES}

Albin RL, Young AB, Penney JB (1989) The functional anatomy of basal ganglia disorders. Trends Neurosci 12:366-375.

Alexander GE, Crutcher MD (1990) Functional architecture of basal ganglia circuits: neural substrates of parallel processing. Trends Neurosci 13:266-271.

Anglade P, Mouatt-Prigent A, Agid Y, Hirsch EC (1996) Synaptic plasticity in the caudate nucleus of patients with Parkinson's disease. Neurodegeneration 5:121-128.

Blandini F, Porter RHP, Greenamyre JT (1996) Glutamate and Parkinson's disease. Mol Neurobiol 12:73-94.

Bolam JP (1992) Preparation of central nervous system tissue for light and electron microscopy. In: Experimental neuroanatomy: a practical approach (Rickwood D, Hames BD, eds), pp 1-29. New York: Oxford UP.

Bouyer JJ, Park DH, Joh TH, Pickel VM (1984) Chemical and structural analysis of the relation between cortical inputs and tyrosine hydroxylase-containing terminals in rat neostriatum. Brain Res 302:267-275.

Calverley RKS, Jones DG (1990) Contributions of dendritic spines and perforated synapses to synaptic plasticity. Brain Res Rev 15:215-249.

Campbell K, Björklund A (1994) Prefrontal corticostriatal afferents maintain increased enkephalin gene expression in the dopaminedenervated rat striatum. Eur J Neurosci 6:1371-1383.

Chen S, Hillman DE (1990) Robust synaptic plasticity of striatal cells following partial deafferentation. Brain Res 520:103-114.

Coggeshall RE (1992) A consideration of neural counting methods. Trends Neurosci 15:9-13.

De Groot DMG, Bierman EPB (1986) A critical evaluation of methods for estimating the numerical density of synapses. J Neurosci Methods 18:79-101.

DeLong MR (1990) Primate models of movement disorders of basal ganglia origin. Trends Neurosci 13:281-285.

Fonnum F, Storm-Mathisen J, Divac I (1981) Biochemical evidence for glutamate as neurotransmitter in corticostriatal and corticothalamic fibres in rat brain. Neuroscience 6:863-873.

Freund TF, Powell JF, Smith AD (1984) Tyrosine hydroxylaseimmunoreactive boutons in synaptic contact with identified striatonigral neurons, with particular reference to dendritic spines. Neuroscience 13:1189-1215.

Geinisman Y, de Toledo-Morrell L, Morrell F (1991) Induction of longterm potentiation is associated with an increase in the number of axospinous synapses with segmented postsynaptic densities. Brain Res 566:77-88.

Gerfen CR, Young III WS (1988) Distribution of striatonigral and striatopallidal peptidergic neurons in both patch and matrix compartments: an in situ hybridization histochemistry and fluorescent retrograde tracing study. Brain Res 460:161-167.

Greenamyre JT, O’Brien CF (1991) N-Methyl-D-aspartate antagonists in the treatment of Parkinson's disease. Arch Neurol 48:977-981.

Groves PM, Linder JC, Young SJ (1994) 5-hydroxydopamine-labeled dopaminergic axons: three-dimensional reconstructions of axons, synapses and postsynaptic targets in rat neostriatum. Neuroscience 58:593-604. 
Gundersen HJG (1977) Notes on the estimation of the numerical density of arbitrary profiles: the edge effect. J Microsc 111:219-223.

Hajji MD, Salin P, Kerkerian-Le Goff L (1996) Chronic dizocilpine maleate (MK- 801) treatment suppresses the effects of nigrostriatal dopamine deafferentation on enkephalin but not on substance P expression in the rat striatum. Eur J Neurosci 8:917-926.

Hanley JJ, Bolam JP (1997) Synaptology of the cortical projection to the ipsilateral and contralateral neostriatum of the rat: relation to the patch-matrix complex. Brain Res Assoc Abstr 14:56.

Harris KM, Kater SB (1994) Dendritic spines: Cellular specializations imparting both stability and flexibility to synaptic function. Annu Rev Neurosci 17:341-371.

Hattori T, McGeer EG, McGeer PL (1978) Fine structural analysis of cortico-striatal pathway. J Comp Neurol 185:347-354.

Hattori T, Takada M, Moriizumi T, Van der Kooy D (1991) Single dopaminergic nigrostriatal neurons form two chemically distinct synaptic types: Possible transmitter segregation within neurons. J Comp Neurol 309:391-401.

Hefti F, Melamed E, Wurtman RJ (1980) Partial lesions of the dopaminergic nigrostriatal system in rat brain: biochemical characterization. Brain Res 195:123-137.

Hersch SM, Ciliax BJ, Gutekunst C-A, Rees HD, Heilman CJ, Yung KKL, Bolam JP, Ince E, Yi H, Levey AI (1995) Electron microscopic analysis of D1 and D2 dopamine receptor proteins in the dorsal striatum and their synaptic relationships with motor corticostriatal afferents. J Neurosci 15:5222-5237.

Hunter A, Stewart MG (1993) Long-term increases in the numerical density of synapses in the chick lobus parolfactorius after passive avoidance training. Brain Res 605:251-255.

Ingham CA (1992) Immunocytochemistry II: post-embedding staining. In: Experimental neuroanatomy: a practical approach (Bolam JP, ed), pp 129-151. Oxford: Oxford UP.

Ingham CA, Hood SH, Arbuthnott GW (1989) Spine density on neostriatal neurons changes with 6-hydroxydopamine lesions and with age. Brain Res 503:334-338.

Ingham CA, Hood SH, Arbuthnott GW (1991) A light and electron microscopical study of enkephalin-immunoreactive structures in the rat neostriatum after removal of the nigrostriatal dopaminergic pathway. Neuroscience 42:715-730.

Ingham CA, Hood SH, Van Maldegem B, Weenink A, Arbuthnott GW (1993) Morphological changes in the rat neostriatum after unilateral 6hydroxydopamine injections into the nigrostriatal pathway. Exp Brain Res 93:17-27.

Ingham CA, Hood SH, Mijnster MJ, Baldock RA, Arbuthnott GW (1997) Plasticity of striatopallidal terminals following unilateral lesion of the dopaminergic nigrostriatal pathway: a morphological study. Exp Brain Res 116:39-49.

Kemp JM, Powell TPS (1971a) The synaptic organization of the caudate nucleus. Philos Trans R Soc Lond B Biol Sci 262:403-412.

Kemp JM, Powell TPS (1971b) The site of termination of afferent fibres in the caudate nucleus. Philos Trans R Soc Lond B Biol Sci 262:413-427.

Lindefors N, Ungerstedt U (1990) Bilateral regulation of glutamate tissue and extracellular levels in caudate-putamen by midbrain dopamine neurons. Neurosci Lett 115:248-252.

Lisman JE, Harris KM (1993) Quantal analysis and synaptic anatomy: integrating two views of hippocampal plasticity. Trends Neurosci 16:141-147.

Maxwell DJ, Christie WM, Brown AG, Ottersen OP, Storm-Mathisen J (1992) Direct observations of synapses between L-glutamateimmunoreactive boutons and identified spinocervical tract neurones in the spinal cord of the cat. J Comp Neurol 326:485-500.

McGeer DL, McGeer EG, Scherer U, Singh K (1977) A glutaminergic corticostriatal pathway? Brain Res 128:369-373.

Meshul CK, Casey DE (1989) Regional, reversible ultrastructural changes in rat brain with chronic neuroleptic treatment. Brain Res 489:338-346.

Meshul CK, Tan S-E (1994) Haloperidol-induced morphological alterations are associated with changes in calcium/calmodulin kinase II activity and glutamate immunoreactivity. Synapse 18:205-217.

Meshul CK, Janowsky A, Casey DE, Stallbaumer RK, Taylor B (1992) Effect of haloperidol and clozapine on the density of "perforated" synapses in caudate, nucleus accumbens, and medial prefrontal cortex. Psychopharmacology (Berl) 106:45-52.

Meshul CK, Stallbaumer RK, Taylor B, Janowsky A (1994) Haloperidolinduced morphological changes in striatum are associated with glutamate synapses. Brain Res 648:181-195.

Ottersen OP (1989) Postembedding immunogold labelling of fixed glutamate: an electron microscopic analysis of the relationship between gold particle density and antigen concentration. J Chem Neuroanat 2:57-66.

Ottersen OP, Storm-Mathisen J (1984) Glutamate- and GABAcontaining neurons in the mouse and rat brain, as demonstrated with a new immunocytochemical technique. J Comp Neurol 229:374-392.

Paxinos G, Watson C (1982) The rat brain in stereotaxic coordinates. London: Academic.

Penny GR, Afsharpour S, Kitai ST (1986) The glutamate decarboxylase-, leucine enkephalin-, methionine enkephalin- and substance P-immunoreactive neurons in the neostriatum of the rat and cat: evidence for partial population overlap. Neuroscience 17:1011-1045.

Phend KD, Weinberg RJ, Rustioni A (1992) Techniques to optimize post-embedding single and double staining for amino acid neurotransmitters. J Histochem Cytochem 40:1011-1020.

Pierce JP, Lewin GR (1994) An ultrastructural size principle. Neuroscience 58:441-446.

Reynolds ES (1963) The use of lead citrate at high $\mathrm{pH}$ as an electron opaque stain in electron microscopy. J Cell Biol 17:208-212.

Seroogy KB, Lundgren KH, Tran TMD, Guthrie KM, Isackson PJ, Gall CM (1994) Dopaminergic neurons in rat ventral midbrain express brain-derived neurotrophic factor and neurotrophin-3 mRNAs. J Comp Neurol 342:321-334.

Small JV (1968) Measurement of section thickness. Paper presented at Fourth European Regional Conference on Electron Microscopy, Rome.

Smith Y, Bennett BD, Bolam JP, Parent A, Sadikot AF (1994) Synaptic relationships between dopaminergic afferents and cortical or thalamic input in the sensorimotor territory of the striatum in monkey. J Comp Neurol 344:1-19.

Somogyi P, Bolam JP, Smith AD (1981) Monosynaptic cortical input and local axon collaterals of identified striatonigral neurons. A light and electron microscopic study using the Golgi-peroxidase transportdegeneration procedure. J Comp Neurol 195:567-584.

Starr MS (1995) Antiparkinsonian actions of glutamate antagonists alone and with L-DOPA: a review of evidence and suggestions for possible mechanisms. J Neural Transm Parkinson's Dis Dementia Sect 10:141-185.

Sterio DC (1984) Estimating numbers, mean sizes and variations in size of particles in 3-D specimens using disectors. J Microsc 134:127-136.

Ungerstedt U, Arbuthnott GW (1970) Quantitative recording of rotational behaviour in rats after 6-hydroxy-dopamine lesions of the nigrostriatal dopamine system. Brain Res 24:485-493.

Voorn P, Jorritsma-Byham B, Van Dijk C, Buijs RM (1986) Dopaminergic innervation of the ventral striatum in the rat: a light and electronmicroscopical study with antibodies against dopamine. J Comp Neurol 251:84-99.

Wilson CJ (1987) Morphology and synaptic connections of crossed corticostriatal neurons in the rat. J Comp Neurol 263:567-580.

Wilson CJ, Groves PM, Kitai ST, Linder JC (1983) Three-dimensional structure of dendritic spines in the rat neostriatum. J Neurosci 3:383-398.

Wright AK, Hutton L, Norrie L, Arbuthnott GW (1995) Topographical patterns of efferents from the 'barrel' cortex in rat. Brain Res Assoc Abstr 12:11.2.

Xu ZC, Wilson CJ, Emson PC (1989) Restoration of the corticostriatal projection in rat neostriatal grafts: electron-microscopic analysis. Neuroscience 29:539-550.

Xu ZC, Wilson CJ, Emson PC (1991) Restoration of thalamostriatal projections in rat neostriatal grafts: an electron microscopic analysis. J Comp Neurol 303:22-34.

Yung KKL, Smith AD, Levey AI, Bolam JP (1996) Synaptic connections between spiny neurons of the direct and indirect pathways in the neostriatum of the rat: evidence from dopamine receptor and neuropeptide immunostaining. Eur J Neurosci 8:861-869. 